\title{
Caste-Category, Residential Locale, and Psychological Well-Being
}

\author{
Rahul Tomer ${ }^{1}$, Dr. Bhagat Singh ${ }^{2 *}$ \\ ${ }^{1}$ Ph.D Research Scholar, Department of Psychology, Meerut College, Meerut, Uttar Pradesh \\ (India) \{Affiliated to C.C.S. University, Meerut (UP)\} \\ ${ }^{2}$ Associate Prof., Department of Psychology, Meerut College, Meerut, Uttar Pradesh (India) \\ (https://orcid.org/0000-0003-4381-8681)
}

\begin{abstract}
*Corresponding Author: Associate Prof., Department of Psychology, Meerut College, Meerut, Uttar Pradesh (India) \{Affiliated to C.C.S. University, Meerut (UP)\}
\end{abstract}

\begin{abstract}
Psychological well-being is defined as the ability of the an individual to use its psychological potential in full. Many factors affect the psychological well-being of an individual in particular and the society at large. Residential locality is one of them. In Indian Society, caste play a major role and affect the social, economic and psychological aspect of an individual. So, the researchers in this study tried to find out the effect of caste category and residential locale on psychological well-being. For this purpose, 438 graduate students (219 from rural areas and 219 from urban areas) were randomly selected. Out of the 438 subjects- 146 subjects each were from general caste, other backward classes and scheduled caste categories. For data collection Psychological Well-Being Questionnaire developed and standardized by Dr. Devendra Singh Sisodia and Pooja Choudhary was used. $2 * 3$ factorial analysis was used. Results showed that the rural areas students have significantly higher PWB than the urban students. Caste category has no effect on PWB and the caste category and locale do not produce any interaction effect on PWB of college students. It can also be concluded that general category rural students have significantly higher PWB than that of urban students.
\end{abstract}

Keywords: Caste Category, Residential locale, Psychological Well-Being

Abbreviations: GC-General Caste Category, OBC-Other Backward Classes Category, SC - Scheduled Caste Category, PWB-Psychological Well-Being

\section{INTRODUCTION}

Psychological well-being (PWB) relates to the positive functioning of a person. It can be defined as the extent to which someone becomes a fully functioning person. (Ryan and Deci, 2001). Psychological well-being is a multidimensional concept. Personality characteristics, emotional regulation, identity and life experience play an important role in enhancing psychological well-being. Psychological well-being can decrease with neuroticism and increase with education, age, extraversion, and consciousness. (Keyes et al., 2002).

Psychological well-being has two essential concepts -the first concept is related to happiness, which balances positivity and negativity. The second concept is cognition, to a large extent, positive satisfaction depends on it (Bradburn, 1969). Some researcher considered psychological well-being as a cognitive component; this is a most effective dimension of positive functioning. Satisfaction with life was interpreted as a complement to happiness, (Andrews and McKennel, 1980).

Psychological well-being has two facets - hedonic and eudemonic (Waterman,1993). Hedonic facets are an indicator of the quality of life. It is based on a person's level of satisfaction and relationship with environmental characteristics. Eudemonic facets related to life having a meaning and a person's degree of self-fulfillment. Research related to life experience has found that type of life experiences and individual interpretations of these experiences to be essential factors of psychological well-being (Heidrich and Ryff, 1993).

Individual's characteristics are affected by the residential area or locale where individual lives. Living conditions is an important factor affecting psychological well-being. (Phillips et al. (2005). Another 
important factor in the level of well-being is satisfaction with the people they live with. This aspect is very important for the health and well-being of the individual, for whom the family becomes a protective factor for their health.

Caste system is so deeply rooted in Indian society that every aspect of social and individual life is highly influenced by this caste system. The caste system which prevails in Hindu religion divides people into vertical hierarchies with 'Brahamin'on the top, 'kshatriya' in the second, 'Vaishyas'in the third and 'Sudras' (Dalits)at the lowest rank. As a person attains caste position by birth, there is no way to move upward by any other means such as acquiring higher education or earning a higher level of income. India's four main castes, or varnas, are subdivided into thousands of specialized subcastes, or jati. The caste system is deeply rooted in rural areas compared to urban areas. Rural People face caste-related discrimination in jobs, living areas, food, and education also. For reservations and other purpose Government of India and state governments categorized various jati into three major term such as General Caste Category (GC), Other Backward Classes Category (OBC) and Scheduled Caste category (SC). In Uttar Pradesh State there are 09 jati included in General Caste category, 160 jati in other backward classes category and 72 jati are included in scheduled caste category (upyojana.net, 2021)

Arnott, (1983) in his review mentioned that in Indian villages, caste might make a difference in leasing behavior. Hazari and Kumar (2003) found that in Hindu society, differences in the average land holdings between high and low caste are not accidental but fundamental to the caste structure. Phillips, et al. (2005) found the impact of a person's residential area on their health, which is being increasingly acknowledged, and there is evidence for the effects of neighborhood, independently of the individual characteristics of the residents. Hussain, et al. (2013) studied the physical and mental health perspectives of first year undergraduate rural university students. There is growing evidence that a sizeable proportion experience poor physical health, and that the prevalence of psychological disorders is higher in rural university students than their community peers.

Hetal (2015) found a significant difference between urban and rural adolescents with regards to their emotional intelligence and psychological wellbeing. Furthermore, the results highlight that urban college student has high psychological well-being, life satisfaction and efficiency than rural college students. Rural college students have high mental health, and sociability, interpersonal relations than urban college students (Waghmare, 2017).

The results of the study (Lata, 2017) depicted that students of rural areas were found significantly higher than students of urban areas on Physical Wellbeing, Emotional Well-being and Social Wellbeing dimensions. However, students of rural and urban areas were found similar on Global Wellbeing and School Well-being. Bajpai (2001) found that scheduled tribe girls were least adjusted compared with backward and general caste girls. Kumar and Singh (2017) found that scheduled caste category teachers were found significantly less satisfied with their job than that of general and other backward caste teachers.

Though there are a lot of studies conducted and are available online on residential locale and Wellbeing/PWB but we found a few studies available online on caste category and psychological wellbeing especially related to Indian context. So, researcher tried to fill that gap and took caste category as independent variable along with residential locale.

Objectives of the study were as follows-

$>$ To study the effect of caste-category on psychological well-being of college students.

$>$ To study the effect of locale on psychological well-being of college students.

$>$ To study the interactional effect of locale and caste category on psychological well-being of college students.

On the basis of review of previous researches, the following hypothesis were framed-

$>$ There is a significant difference between rural and urban college students in terms of their scores on psychological well-being.

$>$ There is a significant difference among GC, OBC and SC students in terms on their scores on psychological well-being.

$>$ There is a significant interactional effect of locale and caste category on psychological well-being. 


\section{Material AND MeTHOD}

\subsection{Research Design}

$2 * 3$ factorial design was used in this research. Details of division of variables were as follows-

\begin{tabular}{|l|l|l|l|l|}
\hline & \multicolumn{4}{|c|}{ Caste - Category (B) } \\
\hline & & B1 (General) & B2 (OBC) & B3 (SC) \\
\hline \multirow{2}{*}{ Locale (A) } & A1 (Rural) & A1*B1 & A1*B2 & A1*B3 \\
\cline { 2 - 5 } & A2 (Urban) & A2*B1 & A2*B2 & A3*B3 \\
\hline
\end{tabular}

\subsection{Sample}

Stratified Random sampling technique was used to collect the data. For this purpose, 609 students were randomly selected. Using SPSS software finally 438 students were selected randomly for the purpose of the study. Out of which there were 146 general, 146 OBC and 146 SC category students. There were 219 male and 219 females in the study. Age range was 15-25 years ( $M=19.3, \mathrm{SD}=1.58)$. All students were graduate students of degree colleges of Meerut City, Uttar Pradesh State (India).

\subsection{Tool Used}

For this purpose, Psychological Well-Being questionnaire developed and standardized by Dr. Devendra Singh Sisodia and Pooja Choudhary was used. It is a five-point rating scale containing 50 items. This scale has a test - retest reliability 0.87 ; internal consistency 0.90 and content validity 0.94 .

\subsection{Procedure of Data Collection}

The researcher called the students into a small group of 08 to 10. After getting the written 'willingly participation consent' from the subjects, they were asked to fill general information like, age, gender, caste category, education stream and residential locale etc. Then the researcher read the instruction of psychological well-being scale before the subjects. There was no time limit, so filled in scale was taken back from the subject as and when he/she finishes the work. The subjects were thanked for their valuable cooperation. As the study come under 'no harm category' only the permission from the head of the institution was taken through the head of the concern departments.

\section{RESUlt AND DisCuSSION}

Data were analyzed with the help of SPSS. To test the hypothesis $2 * 3$ factorial analysis was performed. Table-1 showed two- way ANOVA among caste-category and locate on psychological well-being. F-ratio for locale was $\mathrm{F}(1,432)=4.17, \mathrm{p}=.042$. F-ratio for caste-category was $\mathrm{F}(2,432)$ $=0.245, p=.783$ and value of F-ratio for interaction of locale and caste-category was $F(2,432)=0.806$, $\mathrm{p}=.447$.

Table -2 showing the summary of simple effect of locale. F-ratio for General category rural and urban subjects was $\mathrm{F}(1,432)=4.90, \mathrm{p}=.05$. F-ratio for $\mathrm{OBC}$ category rural and urban subjects was $\mathrm{F}(1,432)$ $=0.384$ and F-ratio for SC category rural and urban subjects was $\mathrm{F}(1,432)=0.494$.

Table -3 showing the analysis of variance for simple effect of caste category. F-ratio for rural areas general, OBC and SC category subjects was $\mathrm{F}(2,432)=0.868$. F-ratio for urban areas general, OBC and $\mathrm{SC}$ category subjects was $\mathrm{F}(2,432)=0.183$.

Figure-1 showing the simple effect of locate. It is clear from the figure that the mean of general category rural subjects is higher than that of urban subjects. This difference between rural and urban general category subjects was significant as also shown in table-2. Though the mean of psychological well-being of $\mathrm{OBC}$ and SC category rural subjects is higher than that of urban subjects but this difference was not significant (as shown in table-2).

Figure-2 showing the simple effect of caste category. It is clear from the figure that the mean of general category rural subjects is higher than the $\mathrm{OBC}$ and SC category subjects but this difference was not significant (as clear from table-3). It is also clear that the mean of psychological well-being of general, OBC and SC category differ slightly. 


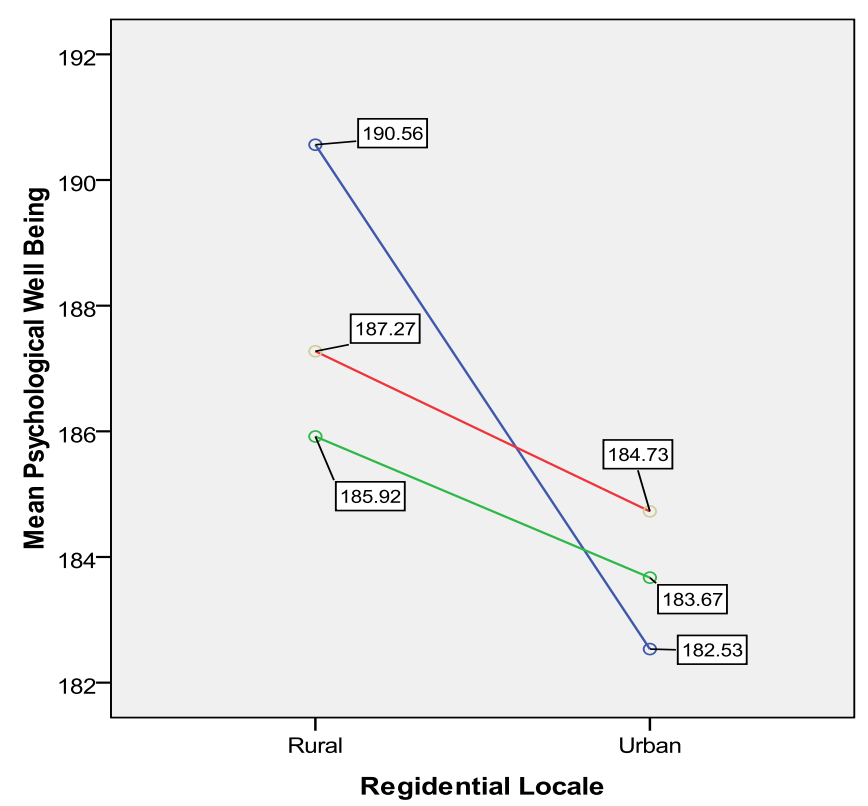

Fig1. Showing the simple effect of Locale

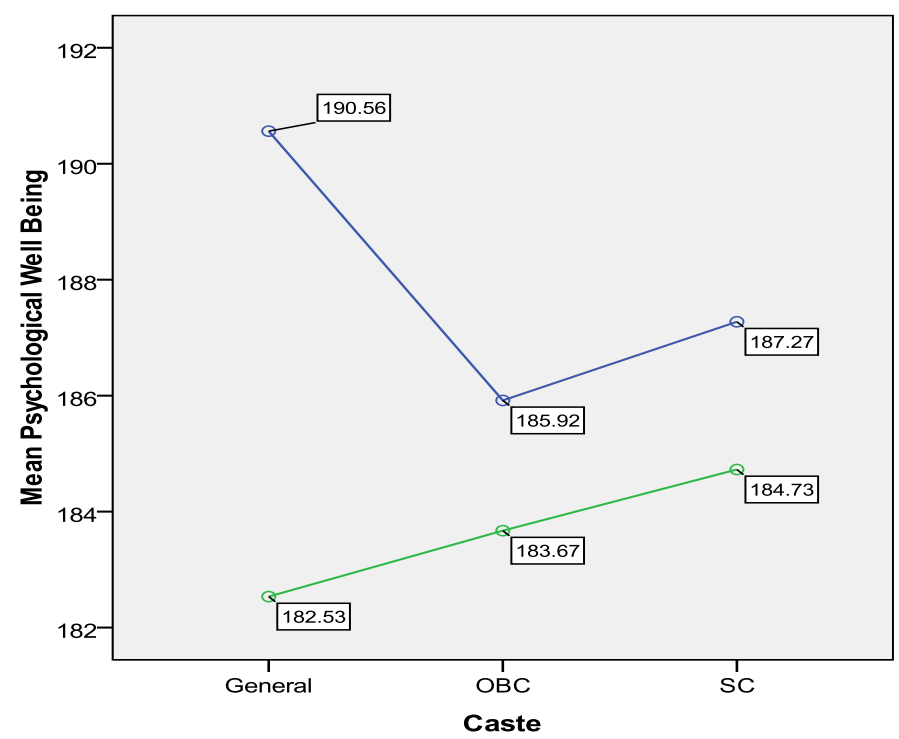

Regidential Locale

- Rural

Urban

Urban

Fig2. Showing the simple effect of Caste Category

Table1. Showing the summary ANOVA Gender and Caste Category on PWB

\begin{tabular}{|l|c|c|c|c|c|}
\hline Source & Sum of Squares & Df & Mean Square & F-ratio & p value \\
\hline Locale $(\mathrm{A})$ & 2000.219 & 1 & 2000.219 & 4.17 & $\mathbf{0 . 0 4 2}$ \\
\hline Caste $(\mathrm{B})$ & 234.959 & 2 & 117.479 & 0.245 & 0.783 \\
\hline Locale * Caste $(\mathrm{A} * \mathrm{~B})$ & 772.986 & 2 & 386.493 & 0.806 & 0.447 \\
\hline Error & 207186.79 & 432 & 479.599 & & \\
\hline
\end{tabular}

Table2. Showing the summary of ANOVA for simple effect of A i.e Locale

\begin{tabular}{|l|c|c|c|c|c|}
\hline Source & Sum of Squares & df & Mean Square & F & Sig. \\
\hline A for B1 & 2352.09 & 1 & 2352.09 & 4.90 & 0.05 \\
\hline A for B2 & 184.22 & 1 & 184.22 & 0.384 & NS \\
\hline A for B3 & 236.96 & 1 & 236.96 & 0.494 & NS \\
\hline Error & 207186.79 & 432 & 479.599 & & \\
\hline
\end{tabular}


Table3. Showing the summary of ANOVA for simple effect of B i.e Caste Category

\begin{tabular}{|l|c|c|c|c|c|}
\hline Source & Sum of Squares & $\boldsymbol{d f}$ & Mean Square & $\boldsymbol{F}$ & Sig. \\
\hline B for A1 & 832.52 & 2 & 416.26 & 0.868 & NS \\
\hline B for A2 & 175.42 & 2 & 87.71 & 0.183 & NS \\
\hline Error & 207186.79 & 432 & 479.599 & & \\
\hline
\end{tabular}

Results showed that mean score of PWB was higher among rural subjects than the urban subjects and this difference was significant. It means that the college students living in rural areas have significantly higher PWB than the subjects living in urban areas. So, we accept our first hypothesis. Results also showed that there was no significant main effect of caste-category and the interaction effect of caste-category and residential locale was also found non-significant. So, we reject our second and third hypothesis. Though the mean score of PWB of GC was higher than that of SC subjects and mean score of PWB of SC subjects was higher than that of OBC subjects but these differences were found non-significant.

Further analysis also shows that the difference in mean score of PWB of rural and urban subjects was only due to the difference in the mean score of PWB of general category rural and urban subjects. The difference between PWB of OBC and SC category rural and urban students was not significant. Reason behind this significant difference may be that -first - the GC students who lives in rural areas have ancestral agricultural land or ancestral occupation which is the main source of earnings of their families and if they will not get job, they will get their share in that ancestral agriculture land or occupation and can earn enough for their livings but this is not so in most case of GC students living in urban areas. They have no such ancestral agricultural land or ancestral business which will help them in their livings. So, this feeling of security in GC rural students and feeling of insecurity in GC urban students may be one of the causes of this significant difference in their PWB.

Second -it may be that the GC rural students feel more satisfied than the urban students as they get better opportunity to get admission in colleges situated at metropolitan cities. If we compare the rural and urban areas on the basis of facilities available to students, we found the gap which was 5 or 10 years before is now filled. Rural areas students have almost same facility as urban students and this give them opportunities not only to get the higher education but also to prepare for various competitive examinations for getting job. So, the felling of satisfaction that they are getting equal opportunities of education and job as urban students make their PWB higher in comparison to the GC urban students. This is also true in case of rural and urban OBC and SC category students.

The PWB of general category is higher than OBC and SC category; SC category PWB is higher than the OBC category but all these differences are not significant. Thus, the overall effect of caste category was found non-significant. The crossing line of rural and urban areas general category make the interaction effect. But the parallel line of OBC and SC category rural and urban areas make not interaction effect. The sum of both sides nullifies the interaction effect as observed in figure -1 . Due to this interaction effect of caste category and locale is not significant.

\section{CONCLusion}

On the basis of result and discussion it can be concluded that the rural areas students have significantly higher PWB than the urban students. Caste category has no effect on PWB and the caste category and locale do not produce any interaction effect on PWB of college students. It can also be concluded that general category rural students have significantly higher PWB than that of urban students. General category urban students showed lowest PWB than the other groups. It should be taken into consideration and study should be conducted to find the causes of this situation.

\section{REFERENCES}

[1] Ryan, R. M. and Deci, E. L., On happiness and human potentials: a review of research on hedonic and eudemonic well-being, Annual Review of Psychology.52,141-166(2001). doi:10.1146/annurev.psych. 52.1.1.141

[2] Keyes, C. L., Shmotkin, D.and Ryff, C. D., Optimizing well-being: the empirical encounter of two traditions, Journal of Personality and Social Psychology. 82(6), 1007-1022 (2002). PMID: 12051575.

[3] N. M. Bradburn, The structure of Psychological Well-Being. Aldine: Chicago,(1969). 
[4] Andrews, F. M. and McKennell, A. C., Measures of self-reported well-being, Social Indicators Research.8, 127-156(1980). http://dx.doi.org/10.1037/0022-3514.69.4.719

[5] Waterman, A. S., Two conceptions of happiness: Contrast of personal expressiveness (eudaimonic) and hedonic enjoyment, Journal of Personality and Social Psychology.64, 678-691(1993).doi: 64. 10.1037/0022-3514.64.4.678.

[6] Heidrich, S. M. and Ryff, C. D., The role of social comparisons processes in the psychological adaptation of elderly adults, Journal of Gerontology.48,127-136(1993). doi: 10.1093/geronj/48.3.P127

[7] Phillips, D. R., Siu, O. L., Yeh, A. G. and Cheng, K. H., The impacts of dwelling conditions on older persons' psychological well-being in Hong Kong: the mediating role of residential satisfaction. Social Science \& Medicine, 60, 2785-797(2005).DOI:10.1016/j.socscimed.2004.11.027https://upyojana.net/uttarpradesh-caste-list/ -Retrieved on 14 September 2021 at 13:08

[8] Arnott, R., [Review of Palanpur: The Economy of an Indian Village, by C. J. Bliss \& N. H. Stern]. The Canadian Journal of Economics / Revue Canadienne d'Economique. 16(4), 733-735(1983). https://doi.org/10.2307/135052

[9] Hazari, R. B., and Kumar. A., Caste, land and livestock holdings in India: An analysis, International Forestry Review. 5, 364-369(2003).doi: 10.1505/IFOR.5.4.364.22655.

[10] Phillips, D. R., Siu, O. L., Yeh, A. G. and Cheng, K. H., The impacts of dwelling conditions on older persons' psychological well-being in Hong Kong: the mediating role of residential satisfaction, Social Science \& Medicine.60, 2785-797(2005). doi:10.1016/j.socscimed.2004.11.027

[11] Hussain, R., Guppy, M., Robertson, S. and Temple, E., Physical and mental health perspective of first year undergraduate rural university students, BMC public health. 13, 848(2013). doi:10.1186/1471-2458-13848

[12] Hetal, A. P., Emotional Intelligence and Psychological Wellbeing of Adolescents, International Journal for Technological Research in Engineering. 2(10), 2333-2336(2015).

[13] Waghmare, D. R., A Study of Psychological Well Being among Urban and Rural College Going Students, Phonix - International Journal for Psychology and Social Sciences.1(3), 1-17 (2017).

[14] Lata., S., A Study of General Well-Being of Adolescents in Relation to their Residential Background Type of School and Academic Achievement, International Journal of Research in Social Sciences.7(11), 22492296(2017).

[15] Bajpai, S., Caste and Belongingness and Adjustment of high school girls, Indian Psychological Review. 56(1), 46-50(2001).

[16] Kumar, A., and Singh, B.,Gender, Caste Categories and Job Satisfaction, Saudi Journal of Business and Management Studies. 2, 804-809(2017).doi: 10.21276

\section{AUTHOR'S BIOGRAPHY}

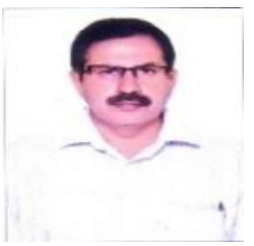

Dr Bhagat Singh, is working as an Associate Prof. in the Department of Psychology, Meerut College, Meerut (Uttar Pradesh) India. He has 20 years of teaching and research experience. He has published 32 papers in peer reviewed, referred Scopus listed /UGC listed journal, 01 book and 05 chapter in edited books. Have attended 52 national and international seminars in India. He is the life member of many academic organizations/associations like Indian Science Congress, Kolkata; Indian Academy of Applied Psychology, Chennai; National Association of Psychological Science, Chandigarh; AIAER, Bhubaneshwar etc. Also, a member of National Positive Psychology Association, New Delhi.

Citation: Tomer, R. \& Singh, B "Caste-Category, Residential Locale, and Psychological Well-Being" International Journal of Humanities Social Sciences and Education (IJHSSE), vol 8, no. 9, 2021, pp. 164-169. doi: https://doi.org/10.20431/2349-0381.0809016.

Copyright: (C) 2021 Authors. This is an open-access article distributed under the terms of the Creative Commons Attribution License, which permits unrestricted use, distribution, and reproduction in any medium, provided the original author and source are credited. 